\title{
PENGARUH BUDAYA ORGANISASI TERHADAP KINERJA PERAWAT PELAKSANA DI RSUD AW SJAHRANIE
}

\author{
Hilda1) $^{1)}$ Arsyawina ${ }^{2)}$ \\ 1,2) Jurusan Keperawatan, Poltekkes Kemenkes Kaltim \\ hildahilda71@gmail.com
}

\begin{abstract}
Nurse performance is a measure of success in achieving the goal of nursing service and a reflection of the quality of services provided. As the spearhead of nursing services in hospitals, nurse performance is a shared value within the framework of a quality culture system. The purpose of this study is to analyze the relationship of organizational culture with the performance of nurse executor in RSUD AW Sjahranie Samarinda.

This was an observational analytical study with cross sectional study design. The 110 nurses who worked as sample in this study. The sample in each room is determined proportionally and taken by simple random sampling. Organizational culture and 7 dimensions of culture are independent variables while the dependent variable is the performance of nurses. Data were collected using structured questionnaires and analyzed using chi square test and multiple logistic regression.

The results showed that organizational culture had a significant effect on the optimum performance of nurses. The organizational culture dimension that has the most influence on the performance of the nurses of the executor is the attention of the details about every job and orientation towards human. Hospital management is expected to socialize the approach of organizational culture element in every application of nursing activity in its working environment.
\end{abstract}

Keywords: Organization culture, Performance - Hospital

\section{ABSTRAK}

Kinerja perawat merupakan ukuran keberhasilan dalam mencapai tujuan pelayanan keperawatan dan cerminan mutu pelayanan yang diberikan. Sebagai ujung tombak pelayanan keperawatan di rumah sakit, kinerja perawat merupakan nilai bersama dalam kerangka sistem budaya mutu. Tujuan penelitian ini adalah menganalisis hubungan budaya organisasi dengan kinerja perawat pelaksana di RSUD AW Sjahranie Samarinda.

Penelitian ini adalah analitik observasional dengan desain cross sectional study. Perawat pelaksana yang berjumlah 110 orang dijadikan sebagai sampel dalam penelitian ini. Sampel di setiap ruangan ditentukan secara proporsional dan diambil secara simple random sampling. Budaya organisasi dan 7 dimensi pendukungnya merupakan variabel bebas sedangkan variabel terikat adalah kinerja perawat. Pengumpulan data menggunakan kuesioner terstruktur dan dianalisis menggunakan uji chi square dan regresi logistik berganda.

Hasil penelitian menunjukkan budaya organisasi berpengaruh secara bermakna dengan kategori kuat terhadap optimalisasi kinerja perawat pelaksana. Dimensi budaya organisasi yang paling berpengaruh terhadap kinerja perawat pelaksana 
adalah perhatian hal hal yang detail setiap melakukan pekerjaan dan orientasi terhadap manusia. Manajemen rumah sakit diharapkan dapat mensosialisasikan pendekatan unsur budaya organisasi dalam setiap penerapan kegiatan keperawatan di lingkungan kerjanya.

Kata kunci : Budaya organisasi, Kinerja - Rumah Sakit

\section{Pendahuluan}

Kinerja yang baik merupakan cerminan mutu pelayanan yang diberikan. Kinerja perawat pelaksana merupakan serangkaian kegiatan perawat dalam memberikan asuhan keperawatan yang merupakan suatu proses atau kegiatan praktik keperawatan yang diberikan oleh perawat pada pasien di berbagai tatanan pelayanan kesehatan dengan menggunakan proses keperawatan, berpedoman pada standar keperawatan dalam lingkup wewenang serta tanggung jawab keperawatan sehingga didapatkan mutu pelayanan keperawatan yang baik. Oleh karena itu seorang perawat perlu melakukan berbagai langkah yang terstruktur dan sistematis berdasarkan proses keperawatan. Proses keperawatan inilah yang nantinya dapat dijadikan tolak ukur evaluasi kinerja perawat (Riyadi, 2007) .

Salah satu proses keperawatan
adalah memberikan asuhan keperawatan dalam pemenuhan kebutuhan dasar manusia. Kebersihan diri dan lingkungan merupakan bagian dari kebutuhan dasar manusia yang harus dipenuhi yang meliputi menyiapkan tempat tidur tertutup dan terbuka, merawat kulit pada daerah yang tertekan, merawat rambut, merawat gigi dan mulut, merawat kuku, higiene vulva dan memandikan pasien. Terpenuhinya kebutuhan kebersihan diri dan lingkungan dapat membangkitkan motivasi klien untuk bekerjasama dalam program keperawatan (Hidayat A;Uliyah $M$, 2012).

Pemeliharaan

hygiene perorangan diperlukan untuk kenyamanan individu, keamanan dan kesehatan. Orang sakit atau orang dengan tantangan fisik memerlukan bantuan perawat untuk melakukan praktik kesehatan yang rutin sedangkan orang sehat mampu memenuhi kebutuhan kesehatannya sendiri (Potter and Perry 2005).

Rumah sakit merupakan suatu organisasi yang memiliki nilai-nilai tertentu, dalam mencapai tujuan rumah sakit memberikan pelayanan yang berkualitas salah satunya ditentukan oleh kinerja perawat (Andriani 2012). Menurut Robbins (2010), nilai-nilai, prinsip, tradisi dan cara-cara bekerja yang dianut bersama oleh para anggota organisasi dan mempengaruhi cara mereka bertindak disebut sebagai budaya organisasi. RSUD AW Sjahranie yang merupakan rumah sakit rujukan tertinggi di provinsi Kalimantan timur dalam profilnya dituliskan bahwa salah satu budaya kerja RSUD AW Sjahranie adalah kepentingan pasien adalah yang utama. Namun dalam melakukan asuhan keperawatan terutama dalam pemenuhan kebutuhan dasar kebersihan diri 
pasien dan lingkungan masih belum optimal.Terbentuknya kinerja perawat yang baik dapat dipengaruhi oleh sistem nilai bersama yang ada pada budaya rumah sakit yang diterima.

Penelitian tentang pengaruh budaya organisasi terhadap kinerja perawat telah banyak dilakukan antara lain penelitian Tsai (2011), Andriani (2012) dan Jacobs et al. (2013) menyatakan bahwa ada hubungan bermakna antara budaya organisasi dengan kinerja karyawan. Penelitian Lina (2014) yang menyatakan bahwa secara parsial budaya organisasi tidak berpengaruh signifikan terhadap kinerja. Demikian juga penelitian (Henry Syauta, Afnan Troena, and Setiawan 2012) yang menyatakan "organizational culture does not influence employee performance".

Menurut Robbins (2010) ada tujuh dimensi yang menjabarkan budaya sebuah organisasi. Masing masing dari ketujuh dimensi tersebut memiliki kisaran mulai dari rendah hingga tinggi, yang artinya sebagai "hal yang sangat tidak lumrah dalam organisasi" (rendah) atau "hal yang sangat lumrah dalam organisasi" (tinggi). Menjabarkan sebuah organisasi dengan menggunakan ketujuh dimensi ini dapat menampilkan gambaran komposit menyangkut budaya organisasi dalam organisasi tersebut. Adapun tujuh dimensi tersebut adalah sebagai berikut : 1) Inovasi dan pengambilan risiko adalah seberapa besar organisasi mendorong para karyawannya untuk bersikap inovatif dan berani mengambil risiko. 2) Perhatian pada detail adalah seberapa dalam ketelitian, analisis dan perhatian pada detail yang dituntut oleh organisasi dari para karyawannya. 3) Orientasi hasil adalah seberapa besar organisasi menekankan pada pencapaian sasaran (hasil), ketimbang pada cara mencapai sasaran (proses). 4) Orientasi manusia adalah seberapa jauh organisasi bersedia mempertimbangkan faktor manusia (karyawan) didalam pengambilan keputusan manajemen. 5) Orientasi tim adalah seberapa besar organisasi menekankan pada kerja kelompok (tim), ketimbang kerja individu, dalam menyelesaikan tugas-tugas. 6) Agresivitas adalah seberapa besar organisasi mendorong para karyawannya untuk saling bersaing, ketimbang saling bekerjasama. 7) Stabilitas adalah seberapa besar organisasi menekankan pada pemeliharaan status quo di dalam pengambilan berbagai keputusan dan tindakan.

Tujuan penelitian ini adalah untuk menganalisis hubungan budaya organisasi dengan kinerja perawat pelaksana di RSUD AW Sjahranie Samarinda.

\section{Metode Penelitian}

Jenis penelitian ini adalah observasional analitik dengan desain cross sectional study yang bertujuan untuk mencari hubungan budaya organisasi dengan kinerja perawat pelaksana di RSUD AW Sjahranie Samarinda. Responden berjumlah 110 perawat pelaksana yang ditentukan secara proporsional kemudian diambil secara simple random sampling Data dikumpulkan menggunakan kuesioner. Data dianalisis univariat, bivariat menggunakan uji chi square 
sedangkan analisis multivariat dengan regresi logistik berganda. Variabel bebas adalah budaya organisasi sedangkan variabel terikat adalah kinerja perawat pelaksana.

\section{Hasil Penelitian}

Tabel 1. Karakteristik Responden

\begin{tabular}{lccc}
\hline Karakteristik & Frekuensi (N=110) & Persentase & Sig \\
\hline Jenis Kelamin & 19 & 17 & 0.848 \\
Laki-Laki & 91 & 83 & \\
Perempuan & & & \\
Umur & 49 & 45 & 0.402 \\
$20-30$ & 49 & 45 & \\
$31-40$ & 12 & 10 & \\
$41-50$ & & & \\
Status & & & \\
$\quad$ Kepegawaian & 44 & 40 & \\
PNS & 66 & 60 & \\
Non PNS & & & \\
Tingkat & & & \\
$\quad$ Pendidikan & 97 & 12 & \\
Vokasi & 13 & & \\
Akademis & & 75 & \\
Lama Bekerja & 82 & 20 & \\
$3-10$ thn & 22 & 5 & \\
$11-20$ thn & 6 & & \\
$21-31$ thn & & & \\
\hline
\end{tabular}

Dari tabel 1 terlihat sebagian besar responden adalah perempuan berlatar belakang pendidikan vokasi (D3) dengan lama bekerja kurang dari 10 tahun. Grafik 1 menunjukkan kualitas penerapan budaya organisasi pada perawat pelaksana. Sebanyak $52 \%$ perawat pelaksana dinilai kuat dalam menerapkan budaya organisasi dalam setiap tindakan keperawatan.
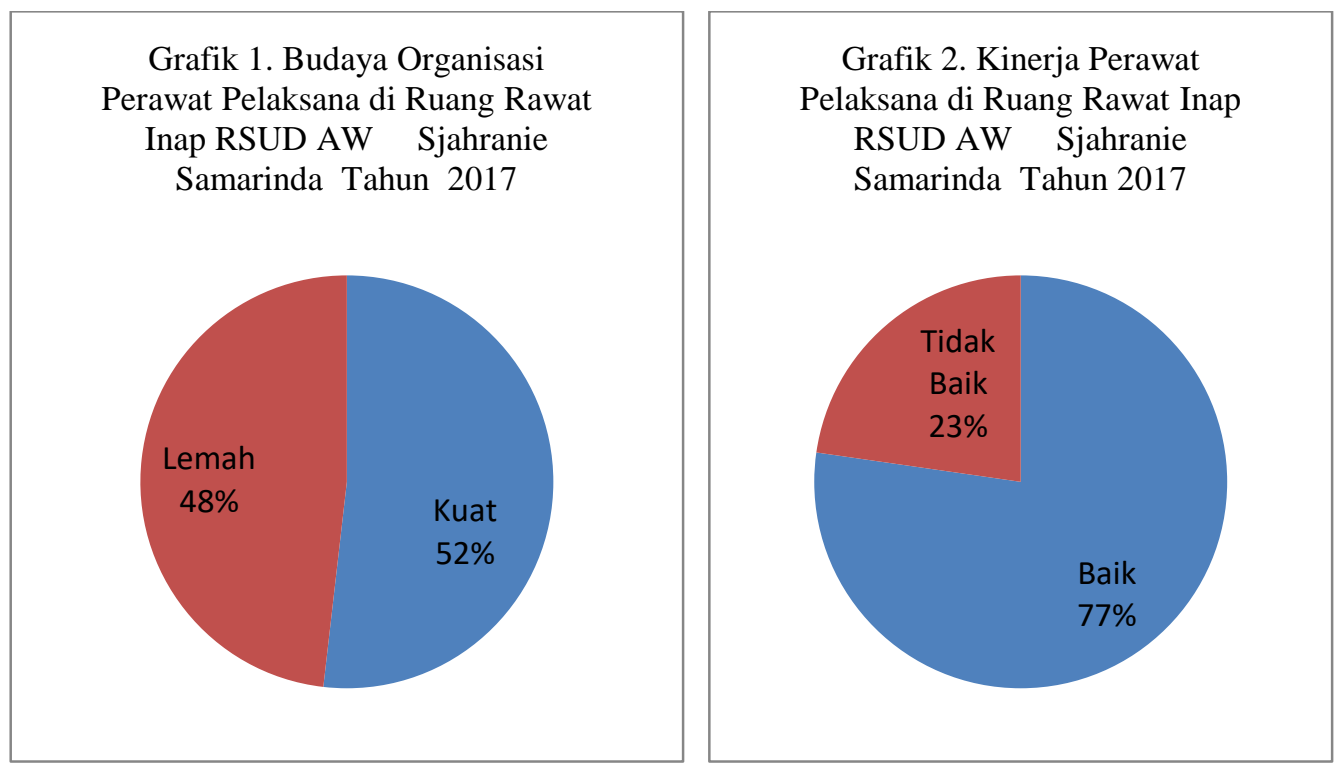
Sedangkan grafik 2 menunjukkan sebagian besar perawat pelaksana $(77 \%)$ mempunyai kinerja yang baik dalam melaksanakan kegiatan keperawatan.

Tabel 2. Distribusi Frekuensi Sub Variabel Budaya Organisasi di Ruang Rawat Inap

RSUD AW Sjahranie Samarinda Tahun 2017

\begin{tabular}{lcc}
\hline SUBVARIABEL & Frekuensi (N=110) & Persentase \\
Inovasi & 88 & 80 \\
Baik & 22 & 20 \\
Kurang & & \\
Perhatian pada detail & 97 & 88,2 \\
Baik & 13 & 11,8 \\
Kurang & & \\
Orientasi hasil & 100 & 90,9 \\
Baik & 10 & 9,1 \\
Kurang & & \\
Orientasi manusia & 75 & 68,2 \\
Baik & 35 & 31,8 \\
Kurang & & \\
Orientasi tim & 59 & 53,6 \\
Baik & 51 & 46,4 \\
Kurang & & \\
Agresivitas & 79 & 71,8 \\
Baik & 31 & 28,2 \\
Kurang & & 66,4 \\
Stabilitas & 73 & 33,6 \\
\hline Kaik & 37 & \\
\hline
\end{tabular}

Tabel 2 diatas menunjukkan analisa subvariabel (dimensi) budaya organisasi. Penilaian subvariabel budaya organisasi yang baik yang dibawah $80 \%$ adalah dimensi agresivitas, orientasi manusia, stabilitas dan orientasi tim.

Tabel 3. Hasil Analisis hubungan dimensi-dimensi budaya organisasi dengan kinerja perawat pelaksana

\begin{tabular}{|c|c|c|c|c|c|c|c|}
\hline \multirow{3}{*}{ Variabel } & & \multicolumn{4}{|c|}{ Kinerja $(\mathrm{N}=110)$} & \multirow{3}{*}{$P$ Value } & \multirow{3}{*}{ OR } \\
\hline & & \multicolumn{2}{|c|}{ Baik } & \multicolumn{2}{|c|}{ Kurang baik } & & \\
\hline & & $\mathrm{N}$ & $\%$ & $\mathrm{~N}$ & $\%$ & & \\
\hline \multirow[t]{2}{*}{ Budaya organisasi } & Baik & 51 & 89 & 6 & 11 & \multirow[t]{2}{*}{0,003} & \multirow[t]{2}{*}{4,750} \\
\hline & Kurang & 34 & 64 & 19 & 36 & & \\
\hline \multicolumn{8}{|l|}{ Sub Variabel } \\
\hline \multirow[t]{2}{*}{ Inovasi } & Baik & 72 & 82 & 16 & 18 & 0,030 & \multirow{2}{*}{3,115} \\
\hline & Kurang & 13 & 59 & 9 & 41 & & \\
\hline \multirow[t]{2}{*}{ Perhatian pada detail } & Baik & 80 & 82 & 17 & 18 & 0,001 & \multirow{2}{*}{7,529} \\
\hline & Kurang & 5 & 38 & 8 & 62 & & \\
\hline \multirow[t]{2}{*}{ Orientasi hasil } & Baik & 77 & 77 & 23 & 23 & 0,827 & \multirow{2}{*}{0,837} \\
\hline & Kurang & 8 & 80 & 2 & 20 & & \\
\hline \multirow[t]{2}{*}{ Orientasi manusia } & Baik & 65 & 87 & 10 & 13 & 0,001 & \multirow{2}{*}{4,875} \\
\hline & Kurang & 20 & 57 & 15 & 43 & & \\
\hline \multirow[t]{2}{*}{ Orientasi tim } & Baik & 49 & 83 & 10 & 17 & 0,120 & \multirow{2}{*}{2,042} \\
\hline & Kurang & 36 & 71 & 15 & 29 & & \\
\hline \multirow[t]{2}{*}{ Agresivitas } & Baik & 66 & 84 & 13 & 16 & 0,015 & \multirow{2}{*}{3,206} \\
\hline & Kurang & 19 & 61 & 12 & 39 & & \\
\hline \multirow[t]{2}{*}{ Stabilitas } & Baik & 57 & 78 & 16 & 22 & 0,777 & \multirow{2}{*}{1,145} \\
\hline & Kurang & 28 & 76 & 9 & 24 & & \\
\hline
\end{tabular}


Tabel 3 menunjukkan secara keseluruhan budaya organisasi berpengaruh terhadap peningkatan kinerja perawat pelaksana dengan OR $=4,750$. Tetapi jika dianalisa per dimensi budaya organisasi terdapat 3 dimensi budaya organisasi yang tidak berpengaruh terhadap kinerja organisasi yaitu orientasi hasil $(p=0,827)$, orientasi tim $(p=0,120)$ dan stabilitas $(p=0,777)$.

Analisis multivariate dilakukan untuk mengetahui model dimensi budaya organisasi dalam mempengaruhi kinerja oranisasi. Dari tabel 3 diperoleh bahwa dimensi orientasi tim memiliki nilai $p$ value lebih kecil dari 0,25 berarti dimensi orientasi tim meskipun tidak berpengaruh masih dapat diikutkan dalam tahap analisis multivariat, sedangkan dimensi orientasi hasil dan stabilitas lebih besar 0,25 maka kedua variabel tersebut tidak dimasukkan tahap analisis multivariat.

Tabel 4. Hasil analisis multivariat regresi logistik

\begin{tabular}{|c|c|c|c|c|c|c|c|c|c|}
\hline & & \multirow{2}{*}{ B } & \multirow{2}{*}{ S.E. } & \multirow{2}{*}{ Wald } & \multirow{2}{*}{$d f$} & \multirow{2}{*}{ Sig. } & \multirow{2}{*}{$\operatorname{Exp}(B)$} & \multicolumn{2}{|c|}{ 95\% C.I EXP(B) } \\
\hline & & & & & & & & Lower & Upper \\
\hline \multicolumn{2}{|c|}{ Tahap Inovasi } & 0,132 & 0,667 & 0,039 & 1 & 0,843 & 1,141 & 0,309 & 4,221 \\
\hline \multirow[t]{4}{*}{1} & Perhatian pada detail & 1,819 & 0,716 & 6,449 & 1 & 0,011 & 6,164 & 1,514 & 25,089 \\
\hline & Orientasi Manusia & 1,182 & 0,563 & 4,405 & 1 & 0,036 & 3,261 & 1,081 & 9,833 \\
\hline & Agresivitas & 0,858 & 0,540 & 2,530 & 1 & 0,112 & 2,360 & 0,819 & 6,796 \\
\hline & Orientasi Tim & 0,277 & 0,535 & 0,268 & 1 & 0,605 & 1,319 & 0,462 & 3,762 \\
\hline \multirow{4}{*}{$\begin{array}{l}\text { Tahap } \\
2\end{array}$} & Perhatian pada detail & 1,857 & 0,689 & 7,262 & 1 & 0,007 & 6,402 & 1,659 & 24,702 \\
\hline & Orientasi Manusia & 1,216 & 0,535 & 5,166 & 1 & 0,023 & 3,375 & 1,182 & 9,632 \\
\hline & Agresivitas & 0,857 & 0,539 & 2,524 & 1 & 0,112 & 2,355 & 0,819 & 6,777 \\
\hline & Orientasi Tim & 0,295 & 0,527 & 0,314 & 1 & 0,575 & 1,343 & 0,479 & 3,770 \\
\hline \multirow{3}{*}{$\begin{array}{l}\text { Tahap } \\
3\end{array}$} & Perhatian pada detail & 1,881 & 0,685 & 7,545 & 1 & 0,006 & 6,558 & 1,714 & 25,093 \\
\hline & Orientasi Manusia & 1,279 & 0,524 & 5,948 & 1 & 0,015 & 3,591 & 1,285 & 10,034 \\
\hline & Agresivitas & 0,862 & 0,539 & 2,556 & 1 & 0,110 & 2,368 & 0,823 & 6,816 \\
\hline \multirow{2}{*}{$\begin{array}{l}\text { Tahap } \\
4\end{array}$} & Perhatian pada detail & 1,858 & 0,668 & 7,739 & 1 & 0,005 & 6,413 & 1,732 & 23,750 \\
\hline & Oreintasi Manusia & 1,471 & 0,506 & 8,442 & 1 & 0,004 & 4,355 & 1,614 & 11,751 \\
\hline
\end{tabular}

Dari tabel 5 step 4 terlihat bahwa pemodelan akhir multivariat dengan syarat $p<0,05$ dan $O R \neq 1$ berarti dimensi perhatian pada detail dan orientasi manusia berpengaruh secara bermakna terhadap kinerja perawat pelaksana. Berdasarkan nilai OR perawat pelaksana yang mempunyai perhatian yang kuat pada detail mempunyai kinerja yang baik adalah 6,413 kali dibandingkan dengan perawat pelaksana dengan perhatian pada detail yang lemah. Sedangkan perawat pelaksana orientasi manusia yang kuat mempunyai kinerja yang baik adalah 4,355 kali dibandingkan dengan perawat pelaksana dengan orientasi manusia yang lemah. Selanjutnya interpretasi pada model dengan 
membuat persamaan regresi logistik yaitu: $y=a+\beta_{1} X_{1}+\beta_{2} X_{2}$ sehingga persamaan menjadi $y=-2.121+1.858$ perhatian pada detail +1.471 orientasi manusia.

\section{Pembahasan}

Budaya memiliki beberapa fungsi di dalam sebuah organisasi antara lain: mempunyai batas pendefinisian peran, sebagai identitas dari anggota organisasi, memfasilitasi penyampaian komitmen ke sesuatu yang lebih besar dari apa yang menarik bagi seorang individu, menambah stabilitas sistem sosial, membantu organisasi menyediakan standar bagi para pekerjanya dan sebagai mekanisme kontrol yang mengarahkan dan membentuk perilaku dan sikap pekerja (Robbins and Coulter 2007).

Hasil penelitian diketahui bahwa budaya organisasi di RSUD AW Sjahranie Samarinda berpengaruh terhadap kinerja perawat pelaksana dan berada pada kategori kuat yaitu $51,8 \%$. Hasil penelitian ini sesuai dengan hasil penelitian yang dilakukan oleh Tsai (2011), Andriani (2012), Jacobs et al. (2013) dan Syauta, dkk (2012) yang menyatakan bahwa budaya organisasi yang kuat akan mempengaruhi kepuasan kerja karyawan dan akhirnya akan meningkatkan kinerja karyawan. Budaya yang kuat adalah budaya yang menanamkan nilai-nilai utama secara kokoh dan diterima secara luas dikalangan para karyawan (Robbins,2010).

Hasil penelitian menunjukkan bahwa $77 \%$ perawat pelaksana di RSUD AW Sjahranie mempunyai kinerja yang baik. Menurut Gibson et al., 2012, faktor-faktor yang mempengaruhi kinerja adalah faktor individu, faktor organisasi dan faktor psikologis. Diantara faktor diatas yang terkait dengan budaya organisasi adalah faktor organisasi. Faktor organisasi digunakan untuk menambah stabilitas sistem sosial, membantu manajemen rumah sakit dalam menyediakan standar bagi para pekerja dan sebagai mekanisme kontrol yang mengarahkan dan membentuk perilaku dan sikap pekerja guna mencapai tujuan organisasi yaitu memuaskan pelanggan, dan berprinsip untuk memberikan produk dan servis yang terbaik.

Dari tujuh subvariabel atau dimensi budaya organisasi yang diteliti dimensi yang paling berpengaruh terhadap kinerja perawat pelaksana adalah perhatian pada detail dan orientasi manusia. Sedangkan dimensi budaya yang lain seperti inovasi, orientasi hasil, orientasi tim, agresivitas dan stabilitas tidak berpengaruh terhadap kinerja. Hasil penelitian sebagian memperkuat hasil penelitian (lqbal et al. 2017) yang menemukan bahwa budaya organisasi memiliki hubungan signifikan terhadap kinerja perawat pelaksana.

Dimensi perhatian pada detail (perincian) dimaknai sebagai sejauh mana perawat pelaksana ketika melaksanakan pekerjaan yang menjadi kompetensinya dapat melaksanakan tugas tersebut dengan presisi, analisis, dan perhatian pada hal-hal detail. Manajemen RSUD AW Syahranie mengunakan SOP, ISO dan KARS dan peraturan internal RS sebagai alat kontrol segala aktivitas yang terjadi di dalam pelayanan $R S$. 
SOP berperan sebagai pedoman tertulis atau tata cara atau tahapan yang dibakukan dan yang harus dilalui untuk menyelesaikan suatu proses kerja tertentu. ISO yang dimiliki oleh RS AW Syahranie adalah ISO 9001:2008. ISO berperan dalam mengukur performa perusahaan dalam 5 parameter yaitu survey kepuasan pelanggan, keluhan pelanggan, audit internal, pengendalian pelayanan tidak sesuai, dan pencapaian sasaran mutu. Peraturan internal RS terdiri atas peraturan tertulis dan tidak tertulis. Peraturan tertulis adalah peraturan yang dibuat mengacu pada peraturan aparaturbsipil negara seperti larangan atau himbauan, jam masuk dan pulang kerja, absen, cuti dan peraturanperaturan umum lainnya. Sedangkan peraturan tidak tertulis adalah peraturan yang biasanya hanya dikomunikasikan secara verbal oleh para pihak dari level manajemen yang lebih tinggi ke para pihak dari level manajemen yang lebih rendah dan untuk urusan yang lebih kecil. Peraturan manajemen RS memiliki fungsi untuk mengatur batasanbatasan mengenai hal yang boleh dan tidak boleh dilakukan dalam organisasi sehingga memperjelas mengenai ruang lingkup dan wewenang kerja bagi setiap individu di dalam melakukan setiap tindakan. Melalui ketiga instrumen tersebut, perawat dituntut untuk selalu bekerja secara cermat dan terperinci. Penerapan dari karakteristik ini dapat dilihat melalui hasil evaluasi kinerja perawat.

Dimensi orientasi manusia yakni sejauh mana keputusan-keputusan menajemen mempertimbangkan efek dari hasil tersebut atas orang yang ada dalam organisasi; Karakteristik budaya organisasi yang berorientasi pada sumberdaya manusia di rumah sakit AW Syahranie dimulai ketika seleksi penerimaan perawat oleh manajemen RS melalui komite keperawatan. Komite keperawatan melakukan seperti pembekalan kemampuan dan pengetahuan bagi perawat, pemagangan serta beberapa hal yang telah dilakukan manajemen RS untuk meningkatkan kenyamanan dan motivasi kerja karyawan. Manajemen RS memberikan masa percobaan dan pelatihan untuk setiap perawat baru.

Menurut Robbins (2010), dimensi orientasi manusia sebagai bagian dari budaya organisasi yang menerapkan prinsip-prinsip keadilan diantara sesama dan terhadap setiap orang didalam organisasi, kebebasan dalam mendorong dan membantu serta memberi jalan bagi rekan lain untuk maju dalam hal pengetahuan, keahlian dan tanggungjawab. Disamping itu kemampuan untuk berkomitmen serta menepati komitmen dan musyawarah dengan rekan lain sebelum mengambil tindakan. Bila nilai-nilai pokok organisasi dapat dipahami secara jelas dan diterima secara luas, para karyawan akan mengetahui apa yang harus dikerjakan dan apa yang diharapkan dari diri mereka, sehingga mereka dapat bertindak dengan cepat untuk mengatasi berbagai permasalahan.

Dimensi orientasi manusia menunjukkan ciri - ciri, sifat, atau karakteristik tertentu yang yang menunjukkan karakteristik budaya organisasi yang dimilikinya. Budaya organisasi merupakan kombinasi dari nilai, keyakinan, pemahaman, dan 
norma perilaku yang dipahami dan dipraktikkan secara bersama-sama oleh karyawan. Umumnya budaya organisasi umumnya tidak dinyatakan secara tertulis tetapi keberadaannya di dalam organisasi tidak dapat disangsikan dan kadang-kadang muncul/dinyatakan dalam bentuk slogan, upacara-upacara yang dilakukan oleh organisasi, sejarah organisasi, cara berpakaian karyawan/pegawai atau tata ruang perkantoran. organisasi tidak bebas nilai berarti pula bahwa organisasi yang satu boleh jadi berbeda dengan organisasi lainnya meski keduanya bergerak dalam bidang yang sama, karena masing-masing organisasi memiliki budaya dan nilai-nilai tersendiri.

Keterbatasan Penelitian

1) Sebagian responden terkesan terburu dalam mengisi kuesioner kemungkinan disebabkan karena keterbatasan waktu dari responden.

2) Deskripsi karakteristik responden tidak signifikan terhadap hasil penelitian, kemungkinan ikut memiliki peran terhadap variabel yang diuji.

Kesimpulan

Kesimpulan dari hasil penelitian ini adalah budaya organisasi berpengaruh signifikan positif terhadap kinerja perawat pelaksana di RS AW Syahranie. Dari tujuh subvariabel atau dimensi budaya organisasi yang diteliti dimensi yang paling berpengaruh terhadap kinerja perawat pelaksana adalah perhatian pada detail dan orientasi manusia.
Saran

1) Penelitian dapat mempertimbangkan pengumpulan data dengan menggabungkan instrumen lainnya

2) Perlu dikaji lebih kuat dan mendalam seberapa besar faktor karakteristik mempengaruhi kinerja karyawan

\section{KEPUSTAKAAN}

Andriani, marlina. 2012. "Hubungan Budaya Organiasi Dan Karakteristik Perawat Dengan Kinerja Perawat Pelaksana Di Ruang Rawat Inap RSUD Dr. Achmad Mochtar Bukit Tinggi." Document Repository Universitas Andalas 68: 375-82..

Gibson, James L, John M Ivancevich, James H Donnelly, and Robert Konopaske. 2012. XXXIII Uma ética para quantos? Organizations Behavior, Structure, Processes.

Hidayat A, Uliyah M. 2012. “ Kebutuhan Dasar Manusia", buku saku praktikum, edisi revisi, EGC, halaman 19-20

Henry Syauta, Jack, Eka Afnan Troena, and Margono Setiawan. 2012. "The Influence of Organizational Culture, Organizational Commitment to Job Satisfaction and Employee Performance (Study at Municipal Waterworks of Jayapura, Papua Indonesia)." International Journal of Business and Management Invention ISSN (Online 1(1): 
2319-8028.

lqbal, Muhammad et al. 2017. "Hubungan Budaya Organisasi Dengan Kinerja Perawat Pelaksana Di Rawat Inap Rs Pmc." Jurnal Endurance 2(3): 285-93.

http://doi.org/10.22216/jen.v2i3.13 55.

Jacobs, Rowena et al. 2013. "The Relationship between Organizational Culture and Performance in Acute Hospitals." Social Science and Medicine 76(1): 115-25.

Lina, Dewi. 2014. "Analisis Pengaruh Kepemimpinan Dan Budaya Organisasi Terhadap Kinerja Pegawai Dengan Reward Sebagai Variabel Moderating." Jurnal Riset Akuntansi Dan Bisnis 14(1): 7797.
Potter, Patricia A, and Anne Griffin Perry. 2005. "Buku Ajar Fundamental Keperawatan: Konsep, Proses, Dan Praktik." Jakarta: EGC: 1376.

Riyadi S. 2007. "Kinerja Perawat Di Rsd Dr. H.Moh Anwar Sumenep Madura Ditinjau Dari Motivasi Kerja." : 32-34

Robbins, Stephen P., and Marry Coulter. 2007. "Manajemen." In Management,

Robbins S, Coulter M. 2010. Manajemen. Edisi kesepuluh, Jilid I. Penerbit Erlangga, Jakarta.

Tsai, Yafang. 2011. "Relationship between Organizational Culture, Leadership Behavior and Job Satisfaction." BMC Health Services Research 11. 